\title{
Smokers' responses to being addressed when smoking in an outdoor voluntary smoke-free zone: An observational study
}

Nienke W. Boderie ${ }^{1+}$, Leonieke J. Breunis ${ }^{2+}$, Isabella Biney ${ }^{1,2}$, Jodie Borsboom ${ }^{1,2}$, Jonne G. ter Braake ${ }^{1,2}$, Laura Koolen ${ }^{1,2}$, Marlou L. A. de Kroon ${ }^{2,3}$, Jasper V. Been ${ }^{1,2,4}$

\section{ABSTRACT}

INTRODUCTION Addressing smokers who smoke in a voluntary smoke-free area is vital to its successful implementation. Many people perceive barriers in addressing smokers due to fear of negative responses. Insights in actual responses are currently lacking.

METHODS This is an observational field study at the voluntary smoke-free zone surrounding the Erasmus MC and two schools in Rotterdam, the Netherlands. In the first month after implementing the zone, Erasmus MC representatives performed rounds to address smokers who were smoking inside the zone. Four people observed addressors for two weeks then they also addressed the smokers. Smokers were classified as employees, patients, students, or other. We noted whether smokers were addressed directly or indirectly, and their verbal and behavioral responses to being addressed. Differences between the responses of the groups were assessed using chi-squared tests.

RESULTS In all, 331 smokers were observed of whom $73 \%$ were addressed directly. Most verbal reactions were positive (46\%) or neutral (18\%). Employees were more likely to respond guiltily, whereas patients more often responded angrily than the others. After being addressed, the majority of smokers either extinguished their cigarette $(41 \%)$ or left to continue smoking outside the smoke-free zone (34\%). ConcLusions Most smokers showed a positive or neutral response when being addressed about smoking inside the smoke-free zone and the majority adapted their behavior to comply with the policy. These findings may help decrease barriers for those in doubt about addressing smokers that fail to comply with a smoke-free policy.

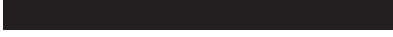 \\ AFFILIATION \\ 1 Department of Public Health, \\ Erasmus MC, Erasmus University \\ Medical Center, Rotterdam, \\ Netherlands \\ 2 Department of Obstetrics and \\ Gynecology, Erasmus MC Sophia \\ Children's Hospital, Erasmus \\ University Medical Center, \\ Rotterdam, Netherlands \\ 3 Department of Health Sciences, \\ University of Groningen Medical \\ Center, Groningen, Netherlands \\ 4 Department of Pediatrics, \\ Division of Neonatology, Erasmus \\ MC Sophia Children's Hospital, \\ Erasmus University Medical Center, \\ Rotterdam, Netherlands \\ + Co-first authors
}

CORRESPONDENCE TO Jasper V. Been. Erasmus University Medical Center, Wytemaweg 80, 3015 CN, Rotterdam, Netherlands. E-mail: j.been@erasmusmc.nl ORCID ID: https://orcid.org/00000002-4907-6466

\section{KEYWORDS}

smoke-free policy, smoking, hospitals, attitude, field study, enforcement, education center

Received: 30 June 2021

Revised: 21 September 2021

Accepted: 23 September 2021

\section{INTRODUCTION}

Tobacco smoking, including secondhand smoke, is responsible for an estimated 8 million people prematurely dying each year and is the leading preventable cause of premature death worldwide ${ }^{1,2}$. Smoke-free policies are implemented to protect bystanders from secondhand smoke exposure and may help to denormalize and demotivate smoking ${ }^{3-6}$.
To regulate smoking in selected outdoor areas, local and national policies are being developed and implemented. In the Netherlands, outdoor areas of educational institutions are expected to be smokefree since August 20207. In anticipation of this national smoke-free regulation and in collaboration with the municipal government, an inner-city outdoor smoke-free zone was implemented 
on 2 September 2019 in Rotterdam. The zone encompasses a university hospital, a university of applied sciences, a high school, and the public road in between. The smoke-free zone was not regulated by law but focused on creating a smokefree norm using clear communication and signage, and via encouraging bystanders to address smokers who were smoking within the zone. Recently, we demonstrated that implementation of the smokefree zone was followed by a $45 \%$ reduction in the number of smokers in the area ${ }^{8}$. At the same time, however, we noted that very few smokers were addressed when smoking within the smoke-free zone. Reluctance to address smokers has been noted by previous studies ${ }^{9-11}$.

Previous research showed that, although the proper addressing of smokers is a key factor for successful implementation of smoke-free zones ${ }^{12}$, many people feel uncomfortable to address smokers due to fear of negative responses ${ }^{13}$. In this study, we aimed to formally assess smokers' responses to being addressed when smoking within the outdoor smoke-free zone. The Strengthening the Reporting of Observational Studies in Epidemiology (STROBE) guidelines were used $^{14}$.

\section{METHODS}

\section{Design and setting}

This observational field study was conducted in September 2019 at the grounds surrounding Erasmus MC, a tertiary hospital in Rotterdam, the Netherlands. The smoke-free zone encompasses the Erasmus MC, two educational institutions, and the public road in between. The zone is indicated with a blue line around it on the street and pavement and by 'Smoke-free generation' banners, signs and tiles (Supplementary file Figure S1). Using the momentum of the implementation of the smoke-free zone, observations were scheduled in the following month. In the first two weeks, representatives of Erasmus MC ('addressors') made rounds to address smokers. Depending on availability, these rounds were prescheduled twice a day for sixty to ninety minutes per round and varied in starting time. In pairs of two the authors (JB, JGtB, IB, LK) were observers from a distance of the addressors and smokers in the smokefree zone. In the next two weeks, one observer acted as addressor, and the other as observer, following the same schedule as the addressors in the first two weeks. Neither the addressors nor the observers received specific training and no scripts were used. Addressors had the option to wear a Smoke-Free Generation vest, identifying them as Erasmus MC volunteers.

\section{Data collection}

In both periods the observer noted the number of smokers present within approximately $5 \mathrm{~m}$ distance of the observers, whether they were addressed and if so, whether this was done directly or indirectly (i.e. smoker was able to overhear another smoker being addressed), the behavioral response to being addressed (positive: extinguished cigarette or continued smoking outside the smoke-free zone; negative: continued smoking at same location, or continued smoking elsewhere inside the smoke-free zone), whether the person addressing wore a Smoke-Free Generation vest and any verbal response (positive: understanding or happy; neutral: guilty or surprised; or negative: angry, cranky, indifferent, starts discussion). Smokers were not addressed if their cigarette was already extinguished or if they were on the phone. Any discrepancies among observers regarding the categorization of responses were discussed immediately until consensus was reached. Any other noteworthy events were recorded in a daily log.

\section{Data analysis}

Smokers were categorized into: patients, employees, students, and others, as described previously ${ }^{8}$. Categorical data are shown as numbers and percentages. Differences between groups were assessed using chi-squared tests.

\section{RESULTS}

In total, 331 smokers were observed. The majority were classified as patients (39\%), employees ( $22 \%)$ or students (21\%). Most smokers were addressed directly (73\%), others indirectly (10\%) or not addressed (17\%). Among the latter group, responses were unobservable, and among the former data were missing for ten verbal and two behavioral responses. Observed verbal reactions were positive in $46 \%(n=121)$, neutral in $18 \%(n=48)$ and negative in $36 \%(n=96)$ (Figure 1$).$ An understanding response was observed most often ( $n=121 ; 43 \%)$, employees more often respond guiltily ( $n=19 ; 73 \%$ of all guilty responses), whereas patients more often responded angrily than others $(n=13 ; 87 \%$ 
Figure 1. Verbal (A) and behavioral responses (B) to being addressed
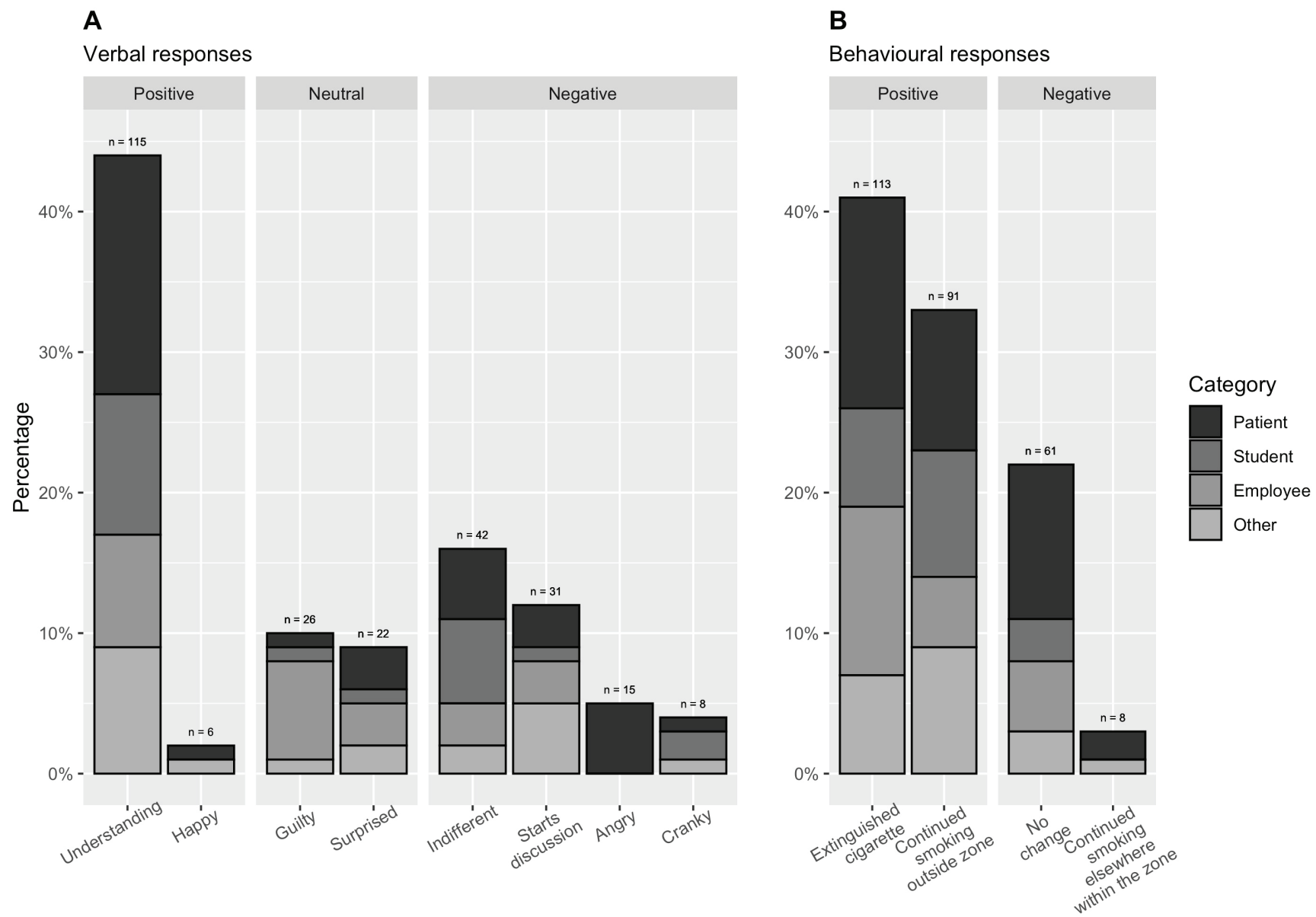

of all angry responses). Verbal responses differed significantly across categories of smokers $\left(X^{2}=29.3\right.$, $\mathrm{p}<0.0001)$. In the second period, more positive responses were observed than in the first ( $52 \% \mathrm{vs}$ $\left.31 \% ; \chi^{2}=0.5, \mathrm{p}=0.001\right)$.

The majority of smokers complied with the smoke-free policy after being addressed, by either extinguishing their cigarette $(41 \%)$ or leaving to continue smoking outside the zone (34\%). Behavioral responses differed significantly across categories of verbal responses $\left(X^{2}=117.7, p<0.001\right.$; Supplementary file Table S1). Smokers who complied with the smoke-free policy $(n=204)$, had a positive verbal response in $59 \%$, a neutral verbal response in $24 \%$ and a negative verbal response in $17 \%$ of the cases. Almost all smokers who did not comply with the smoke-free policy $(n=69)$ had a negative verbal response $(n=62 ; 90 \%)$. There were no important differences in the proportion of smokers complying with the policy or having a positive verbal response according to whether those addressing wore a Smoke-Free Generation vest or not ( $79 \%$ vs $69 \%$; and $41 \%$ vs $50 \%$, respectively).

In the log, observers noted that they felt that smokers more often responded positively when being addressed in a positive (friendly and calm, e.g. 'Did you know that this is a smoke-free zone?') rather than a negative (judgmental) manner (e.g. 'You are not allowed to smoke here'). Furthermore, they noted that if one person was smoking in the smoke-free zone, this appeared to attract other smokers. Finally, observers felt that addressing employees was easier than addressing students and patients, and that addressing a single smoker was easier than addressing a group of smokers.

\section{DISCUSSION}

In this study, addressing people who smoked inside 
a voluntary smoke-free zone often elicited a positive or neutral response and increased compliance with the smoke-free policy. Our findings are in line with previous research indicating that a positive approach towards smokers in a smoke-free zone more often results in a positive response ${ }^{15}$. Whereas fear of confrontation and aggression from smokers is a barrier perceived especially among healthcare staff ${ }^{11}$, our study indicates that this fear is often ungrounded.

The fact that representatives of Erasmus MC, among whom where members of the board, addressed smokers may have contributed to the successful implementation of the smoke-free zone, and also might explain the guilty response among many smoking employees. Clear signage in the smoke-free zone likely contributed to smokers' awareness of the social norm ${ }^{16}$, possibly explaining the high proportion of understanding verbal responses. Changing the social norm in a smoke-free zone is a fundamental part of the implementation. Compliance with social norms increases with the number of others expecting a person to comply with the norm ${ }^{17}$. Culture plays an important role in this process, and it is unclear to what degree our findings are generalizable to other locations. However, we would like to argue that in any situation where smoke-free zones are implemented, changing the social norm is an important step. Addressing smokers can contribute to this, despite cultural differences. Furthermore, the addressors quickly gained experience in addressing smokers, which might have resulted in more positive responses of smokers being addressed. Combined with a positive approach, a positive response is likely. Finally, the indifference in the results when using a Smoke-Free Generation vest stresses that anyone can address smokers.

\section{Strengths and limitations}

The strength of this study lies within the repeated measurements on alternating days and times. Furthermore, during observations at least two researchers were present to ensure quick resolution of conflicting observations. It should be noted that those responding angrily to being addressed were often patients. A rather consistent group of smoking patients seated at a particular bench within the zone was addressed daily and this caused frustration. After several days it was decided to no longer address this group, which may have resulted in an underrepresentation of negative responses. However, including them would also be problematic as this group consisted largely of the same people every day. Double counting may have also occurred. Further limitations are the short timeframe between implementation of the zone and this study, and the homogeneity of addressors in the second two observation-weeks (e.g. female medical students).

\section{Future research}

More in-depth research is needed to assess how smokers actually experience being addressed, what they feel they need to adapt their behavior and why they feel a certain way after being addressed. Such information is an important step in developing recommendations for effective addressing and increasing compliance with voluntary smoke-free policies. Additionally, further research on how to strengthen self-efficacy of addressors is important, as the feeling that addressing smokers is easy, is an important predictor of doing so $^{18}$.

\section{CONCLUSIONS}

Whereas many people may experience barriers to addressing smokers who smoke within a smokefree zone, our study shows that addressing smokers often elicits positive responses and may help increase compliance with the smoke-free policy. A positive, calm and non-judgmental approach seems to be key in addressing. Our findings may help increase selfefficacy of those reluctant to address smokers in smoke-free zones.

\section{REFERENCES}

1. World Health Organisation. Tobacco. July 26, 2021. Accessed September 21, 2021. https://www.who.int/en/ news-room/fact-sheets/detail/tobacco.

2. Öberg M, Jaakkola MS, Woodward A, Peruga A, PrüssUstün A. Worldwide burden of disease from exposure to second-hand smoke: a retrospective analysis of data from 192 countries. Lancet. 2011;377(9760):139-146. doi:10.1016/S0140-6736(10)61388-8

3. Schreuders M, Kuipers MA, Mlinarić M, et al. The association between smoke-free school policies and adolescents' anti-smoking beliefs: Moderation by family smoking norms. Drug Alcohol Depend. 2019;204:107521. doi:10.1016/j.drugalcdep.2019.06.023

4. Mons U, Nagelhout GE, Allwright S, et al. Impact of national smoke-free legislation on home smoking bans: findings 
from the International Tobacco Control Policy Evaluation Project Europe Surveys. Tob Control. 2013;22(e1):e2-e9. doi:10.1136/tobaccocontrol-2011-050131

5. Faber T, Kumar A, Mackenbach JP, et al. Effect of tobacco control policies on perinatal and child health: a systematic review and meta-analysis. Lancet Public Health. 2017;2(9):e420-e437. doi:10.1016/S2468-2667(17)30144-5

6. Lightwood JM, Glantz SA. Declines in acute myocardial infarction after smoke-free laws and individual risk attributable to secondhand smoke. Circulation. 2009;120(14):1373-1379. doi:10.1161/CIRCULATIONAHA.109.870691

7. Ministry of Health, Welfare and Sport. Nationaal Preventieakkoord: Naar een gezonder Nederland. November 23, 2018. Accessed September 21, 2021. https://www.rijksoverheid.nl/ministeries/ministerievan-volksgezondheid-welzijn-en-sport/documenten/ convenanten/2018/11/23/nationaal-preventieakkoord

8. Breunis LJ, Bebek M, Dereci N, de Kroon MLA, Radó MK, Been JV. Impact of an Inner-City Smoke-Free Zone on Outdoor Smoking Patterns: A Before-After Study. Nicotine Tob Res. 2021;23(10):1708-1715. doi:10.1093/ntr/ntab109

9. Xiao D, Wang C, Chen H, Hajek P. Making Hospitals in China Smoke-Free: A Prospective Study of Implementing the New Standard. Nicotine Tob Res. 2013;15(12):20762080. doi:10.1093/ntr/ntt098

10. Garritsen HH, Rozema AD, van de Goor IAM, Kunst AE. Smoke-Free Sports in The Netherlands: Why Most Sports Clubs Have Not Adopted an Outdoor Smoke-Free Policy. Int J Environ Res Public Health. 2021;18(5):2454. doi:10.3390/ijerph18052454

11. Shipley M, Allcock R. Achieving a smoke-free hospital: reported enforcement of smoke-free regulations by NHS health care staff. J Public Health (Oxf). 2008;30(1):2-7. doi:10.1093/pubmed/fdn004

12. Zhou L, Niu L, Jiang H, Jiang C, Xiao S. Facilitators and Barriers of Smokers' Compliance with Smoking Bans in Public Places: A Systematic Review of Quantitative and Qualitative Literature. Int J Environ Res Public Health. 2016;13(12):1228. doi:10.3390/ijerph13121228

13. Ratschen E, Britton J, McNeill A. Smoke-free hospitals the English experience: results from a survey, interviews, and site visits. BMC Health Serv Res. 2008;8:1-9. doi:10.1186/1472-6963-8-41

14. von Elm E, Altman DG, Egger M, et al. The Strengthening the Reporting of Observational Studies in Epidemiology (STROBE) statement: guidelines for reporting observational studies. Bull World Health Organ. 2007;85(11):867-872. doi:10.2471/blt.07.045120

15. Poland BD, Stockton L, Ashley MJ, et al. Interactions Between Smokers and Non-Smokers in Public Places: A Qualitative Study. Can J Public Health. 1999;90(5):330333. doi:10.1007/BF03404522

16. Platter HN, Pokorny SB. Smoke-free signage in public parks: impacts on smoking behaviour. Tob Control. 2018;27(4):470473. doi:10.1136/tobaccocontrol-2016-053624

17. Dechesne F, Di Tosto G, Dignum V, Dignum F. No smoking here: values, norms and culture in multi-agent systems. Artif Intell Law (Dordr). 2013;21(1):79-107. doi:10.1007/s10506-012-9128-5

18. Lazuras L, Zlatev M, Rodafinos A, Eiser JR. Smokers' compliance with smoke-free policies, and non-smokers' assertiveness for smoke-free air in the workplace: a study from the Balkans. Int J Public Health. 2012;57(5):769775. doi:10.1007/s00038-012-0338-0

\section{CONFLICTS OF INTEREST}

The authors have each completed and submitted an ICMJE Form for Disclosure of Potential Conflicts of Interest. The authors declare that they have no competing interests, financial or otherwise, related to the current work. J. Been reports funding from the Dutch Heart Foundation, Lung Foundation Netherlands, Dutch Cancer Society, Dutch Diabetes Research Foundation, and Netherlands Thrombosis Foundation. J. Been also reports being chair of the Taskforce Smokefree Erasmus MC who co-initiated the smoke-free zone; and member of the National Taskforce Smokefree Start.

\section{FUNDING}

This study was funded by a joint grant from the Dutch Heart Foundation, Lung Foundation Netherlands, Dutch Cancer Society, Dutch Diabetes Research Foundation and the Netherlands Thrombosis Foundation (Grant number: 2.1.19.010).

\section{ETHICAL APPROVAL AND INFORMED CONSENT}

The Medical Ethics Committee of the Erasmus MC declared that the rules of the Medical Research Involving Human Subjects Act (The Dutch: WMO) did not apply to this study (MEC-2019-0585). Informed consent was not sought in addressing smokers in the smoke-free zone, so as not to bias their responses.

\section{DATA AVAILABILITY}

The data supporting this research are available from the authors on reasonable request.

\section{AUTHORS' CONTRIBUTIONS}

NWB and $\mathrm{DB}$ developed the project, supervised the research, conducted statistical analysis and drafted the manuscript. IB, JB, JGtB and LK conducted the observations and obtained the data. MLAdK supervised the research and JVB supervised the research and drafting of the manuscript. All authors critically reviewed the manuscript.

\section{PROVENANCE AND PEER REVIEW}

Not commissioned; externally peer reviewed. 